\title{
A política internacional da CGTP e da CUT: Etapas, temas e desafios
}

The international policy of CGTP and CUT: Stages, themes and challenges La politique internationale de la CGTP et de la CUT : étapes, thèmes et défis

\section{Hermes Augusto Costa}

\section{(Q) OpenEdition}

\section{Journals}

Edição electrónica

URL: http://journals.openedition.org/rccs/1024

DOI: $10.4000 /$ rccs. 1024

ISSN: 2182-7435

\section{Editora}

Centro de Estudos Sociais da Universidade de Coimbra

\section{Edição impressa}

Data de publição: 1 Junho 2005

Paginação: 141-161

ISSN: 0254-1106

\section{Refêrencia eletrónica}

Hermes Augusto Costa, "A política internacional da CGTP e da CUT: Etapas, temas e desafios ", Revista Crítica de Ciências Sociais [Online], 71 | 2005, colocado online no dia 01 outubro 2012, criado a 01 maio 2019. URL : http://journals.openedition.org/rccs/1024 ; DOI : 10.4000/rccs.1024 


\section{A política internacional da CGTP e da CUT: Etapas, temas e desafios'}

Apesar de existir enquanto política no seio das organizações sindicais nacionais, a política de relações internacionais (PRI) configura-se, todavia, como "parente pobre" do sindicalismo nacional. Depois de enunciar brevemente, na primeira parte, alguns dos obstáculos actuais à construção de uma PRI, este texto debruça-se, na segunda parte, sobre o espaço que as duas principais centrais sindicais de Portugal e do Brasil (a CGTP e a CUT, respectivamente) vêm conferindo à PRI. Partindo do trabalho de investigação realizado nos últimos 5 anos junto daquelas organizações sindicais, propõe-se uma distribuição das fases da PRI da CGTP e da CUT, sintetizando-se, na terceira parte, algumas semelhanças e diferenças entre ambas a esse respeito.

\section{Introdução}

Este texto analisa o espaço reservado pelo sindicalismo nacional à construção de uma política de relações internacionais (PRI). Como é sabido, a transnacionalização da actividade sindical, quer seja conduzida por organizações sindicais nacionais (aspecto que aqui se privilegia), quer por organizações transnacionais, não é um tema novo. Com efeito, apesar de, na sua origem, o movimento operário ter adquirido uma expressão organizada sobretudo em Inglaterra, ele foi concebido como internacional em estrutura e como internacionalista em objectivo (Waterman, 1998: 17; Hobsbawm, 1988: 10), tendo, pois, a "retórica do internacionalismo" sido sempre parte integrante da narrativa sindical (MacShane, 2004: viii; Pasture e Verberckmoes, 1998: 20; Munck, 2002: 136). Porém, não só ao longo do século XIX, como também no século XX, aos discursos internacionalistas acabaram por corresponder sobretudo práticas de recorte nacional.

\footnotetext{
${ }^{1}$ Uma primeira versão deste texto foi apresentada ao VIII Congresso Luso-Afro-Brasileiro de Ciências Sociais - A Questão Social no Novo Milénio -, Coimbra, 16 a 18 de Setembro de 2004. A informação empírica nele contida é apenas parte de uma ampla investigação do autor sobre a transnacionalização dos discursos e das práticas sindicais das duas principais centrais sindicais de Portugal e do Brasil, respectivamente a CGTP e a CUT, realizada no âmbito da sua tese de doutoramento.
} 
Mesmo as estruturas sindicais de "vocação" internacional, como as Internacionais Operárias, constituídas a partir de 1864, assim como as confederações sindicais mundiais surgidas na sequência da Segunda Guerra Mundial, não foram capazes de fazer corresponder às estruturas internacionais que lhes deram nome objectivos internacionalistas. Por um lado, as divergências internas, o fervor colectivo ou o dogma partidário ${ }^{2}$ foram apenas algumas das contrariedades que, entre o final do século XIX e as primeiras décadas do século XX, atravessaram as Internacionais Operárias. Por outro lado, e como reflexo da Guerra Fria, as duas confederações sindicais mundiais que nos últimos 50-60 anos dominaram o panorama sindical mundial - a Federação Sindical Mundial (FSM), constituída em 1945, e a Confederação Internacional dos Sindicatos Livres (CISL), constituída em 1949 - acabaram por não ser portadoras de projectos sindicais internacionais efectivamente unificadores. Além disso, mesmo com a queda do Bloco de Leste, não é de crer que a "vitoriosa" CISL (composta por cerca de 160 milhões de membros filiados) tenha conseguido ela própria libertar-se de um problema político estrutural: ser uma confederação composta por organizações sindicais nacionais habituadas a pensar e a actuar tendo por referência o Estado-nação.

Devo referir, todavia, que o contexto em que analiso o lugar ocupado pela PRI nas estratégias das centrais sindicais nacionais é um contexto de intensificação dos processos de globalização (sobretudo dos processos de globalização da economia que superam o marco de regulação nacional e desafiam os sindicatos a transnacionalizarem as suas acções) e já não um mero contexto de internacionalização, onde pontificaram as relações entre Estados-Nação e em que a linguagem de classe do operariado foi construída em bases nacionais ou mesmo locais (Thompson, 1987; Hobsbawm, 1988; Estanque, 2000). Por outro lado, convém ainda alertar para o facto de uma análise da PRI das organizações sindicais nacionais ser também inevitavelmente condicionada pelas concepções político-ideológicas e até mesmo alinhamentos partidários sustentados pelas centrais sindicais no plano nacional.

Tendo presentes estes dois aspectos - o contexto de globalização em que reactivamente se movem as organizações sindicais, assim como as influências dos projectos político-ideológicos nacionais na definição da própria PRI -, centro-me na importância atribuída pelas duas maiores organiza-

\footnotetext{
${ }^{2}$ Convirá não esquecer que, apesar de conter ambições de emancipação e solidariedade operária internacional, o próprio slogan "Proletários de todos os países, uni-vos!" em que culmina o Manifesto Comunista (1848) de Marx e Engels visava menos uma organização internacional de sindicatos e mais a organização de um partido operário e comunista.
} 
ções sindicais de Portugal e do Brasil (respectivamente, a Confederação Geral dos Trabalhadores Portugueses, CGTP, e a Central Única dos Trabalhadores, CUT) a uma PRI. ${ }^{3}$ Partindo da documentação recolhida e das entrevistas realizadas nos últimos 5 anos junto das duas centrais sindicais (ver adiante notas 5 e 6), e após identificar alguns dos obstáculos com que a PRI se confronta, proponho uma periodização da PRI de ambas as organizações. Depois de caracterizadas essas fases da PRI de cada central sindical e salientados os temas que as compõe, identifico algumas semelhanças e diferenças entre a PRI da CGTP e da CUT e proponho ainda alguns desafios emergentes associados a essa política.

\section{Por que é tão difícil construir uma política de relações internacionais?} Como já referi, pretendo dar conta do modo com a CGTP e a CUT orientam a sua acção para a construção de uma PRI, avaliando que espaço têm reservado a essa política desde que se constituíram (a CGTP em 1970 e a CUT em 1983). A ideia é, pois, a de averiguar como duas organizações de âmbito nacional se posicionam perante níveis de intervenção transnacional. ${ }^{4}$

Se, a partir "de cima" (plano transnacional), as dificuldades são indisfarçáveis, como assinalei na secção introdutória, a partir "de baixo" (plano nacional), o cenário não parece ser mais favorável. Com efeito, os obstáculos à construção de uma PRI por parte das organizações sindicais nacionais são de vária ordem: em primeiro lugar, é grande a prioridade concedida às políticas de âmbito nacional, tendo em conta que é no plano nacional que regimes jurídicos, salários e condições de trabalho são determinados. Esse

\footnotetext{
3 A escolha destas duas centrais sindicais para uma análise comparada prendeu-se com o facto de: estarmos perante centrais sindicais de países com passados políticos semelhantes, isto é, atravessados por décadas de ditadura; a CGTP e a CUT terem desempenhado um papel fulcral no derrube dessas ditaduras e na construção da democracia, falarem a mesma língua, serem as mais representativas e mediáticas em ambos os países, possuírem estatutos assentes em premissas ideológicas muito próximas (onde pontifica o combate ao capitalismo e a defesa dos valores do socialismo) e que concebem o sindicalismo como um actor-chave de transformação social, etc. No entanto, o facto de serem muito escassos os contactos e os projectos conjuntos entre as duas centrais sindicais sugere igualmente que estamos perante duas realidades sindicais muito distintas entre si. Assim, não só as semelhanças mas também as diferenças entre os dois sindicalismos - evidentes, por exemplo, no modo como se processaram as mudanças da legislação laboral na sequência das transições das ditaduras para as democracias, no grau de informalização que perpassa as relações laborais, na forma como a organização sindical está formalmente estruturada nos dois países, no modo como as estruturas sindicais foram influenciadas e influenciaram as estruturas partidárias, etc. - constituíram um pretexto para a comparação transnacional.

${ }^{4}$ Refiro-me a todas as formas de intervenção e cooperação transnacional (ocorram estas no plano regional, sectorial, empresarial ou internacional ou ainda combinando simultaneamente alguns destes subníveis da esfera transnacional), que a CGTP e a CUT normalmente designam por "assuntos internacionais", "acção internacional" ou "política internacional". Para simplificar, uso neste texto a expressão PRI.
} 
facto contribui para realçar as diferenças entre países quer quanto à capacidade para mobilizar trabalhadores, quer quanto à influência dos factores políticos, ideológicos e culturais na organização sindical; em segundo lugar, são muito escassas a reflexão e produção teóricas a respeito do sindicalismo transnacional, o que se explica, em parte, pelo reduzido número de "trocas" sindicais transnacionais; em terceiro lugar, o volume de recursos financeiros ao dispor das organizações sindicais para empreenderem iniciativas de cooperação transnacional é igualmente bastante escasso; em quarto lugar, a solidariedade operária entre organizações de diferentes partes do mundo é insuficientemente valorizada, em detrimento da (por vezes excessiva) ênfase colocada em visões sindicais opostas e competitivas entre o sindicalismo do Norte (países desenvolvidos) e o sindicalismo do Sul (países subdesenvolvidos); em quinto lugar, assiste-se a uma intensificação da lógica exploradora exercida por parte das multinacionais sobre a classe trabalhadora; em sexto lugar, e porventura apenas com a excepção da OIT, não se vislumbram instituições de governação política global capazes de defender transnacionalmente os interesses de trabalhadores e sindicatos; em síntese, não se formou ainda em redor do sindicalismo uma duradoura identidade sindical transnacional (Santos e Costa, 2004: 19-21; Costa, 2005b: 4-6).

Estes e outros obstáculos à construção de uma PRI não são exclusivos de nenhum país/região, mas antes o resultado de dificuldades de afirmação sindical que ocorrem partout. Com efeito, também os meus entrevistados portugueses e brasileiros acabaram por se fazer eco de alguns deles. Primeiro que tudo, os sindicalistas da CGTP e da CUT - e desde logo, note-se, os responsáveis pelo departamento internacional de cada uma das centrais sindicais, que foram objecto principal da minha análise - reconheceram que a PRI ocupa um espaço muito modesto no conjunto das políticas da central sindical, uma vez que estas políticas estão sobretudo voltadas para as lutas que ocorrem no interior dos respectivos países. As afirmações seguintes dão testemunho disso:

Perante o deficiente conhecimento do que é o movimento sindical internacional, numa escala de 1 a 10 eu não the atribuiria mais do que 2, mas mais a pender para o 1 do que para o 2. (Secretário internacional da CGTP, entrevista, Março de 2001, Lisboa, Sede da CGTP)

À CGTP-IN compete, em primeiro lugar, a defesa e promoção dos interesses dos trabalhadores de Portugal, razão de ser da sua própria existência. Daí resulta que o fundamental da sua acção se desenvolva no quadro nacional, ancorada num esforço permanente nos locais de trabalho, lutando para que esses objectivos sejam uma realidade. (CGTP, 2003a: 1) 
Temos que perceber primeiro a amplitude dos nossos problemas para podermos discutir as questões internacionais (Vicentinho, ex-presidente da CUT, em entrevista ao Boletim Mercosul, 17, Fevereiro de 2000, p. 3);

O espaço prioritário para qualquer sindicato é o nacional, em primeiro lugar, é a empresa, é a categoria, é a cidade, é a região, é o país e só depois é que vem o internacional. (Secretário de relações internacionais da CUT, entrevista, Junho de 2000, São Paulo, Sede da CUT)

As práticas das centrais sindicais, ainda que se tenham fortalecido por lógicas internacionalistas, estão presas a uma perspectiva nacional. (Pesquisador do CEDEC, entrevista, Junho de 2000, São Paulo, CEDEC)

Nós não podemos esquecer que a abertura mundial do Brasil é um negócio muito recente. A gente conheceu a ditadura de 1964 a 1985. Foi uma ditadura e a oportunidade de conhecimento fora do Brasil era muito restrita. Daqui só saíam praticamente para fazer cursos nas escolas de formação lá em Washington, lá na AFL-CIO [...]. Nós temos uma geração toda no interior da CUT que faz parte dessa herança [...]. A nossa formação social, cultural, era uma formação muito fechada. (Secretário de Organização da CUT, entrevista, Junho de 2000, São Paulo, Sede da CUT)

Ainda assim, os sindicalistas da CGTP e da CUT reconhecem que, apesar de modesta e de constituir uma "extensão" das políticas de âmbito nacional, existe autonomamente (com um departamento próprio) uma PRI em cada uma das centrais sindicais. Das características que esses sindicalistas consideram ser as que melhor definem uma PRI destaco as seguintes: 1) a regularidade das acções de âmbito internacional; 2) a solidariedade enquanto valor que deve estar sempre subjacente a tais acções; 3 ) os apoios financeiros para concretização e consolidação das iniciativas transnacionais; 4) a definição de objectivos e estratégias de intervenção internacional; 5) a selecção de aliados para pôr em prática esses objectivos; 6) ou ainda a utilização de instrumentos/procedimentos quer para alcançar os objectivos, quer para maximizar a relação com os aliados.

Porém, foi curioso observar que, ao mesmo tempo que ensaiavam definir os conteúdos de uma PRI, os sindicalistas da CGTP e da CUT "tropeçavam" inevitavelmente nos obstáculos ao exercício de uma PRI. Por exemplo: ao invocarem a importância da regularidade de acções de âmbito internacional, constatavam, em simultâneo, que as referidas acções são mais esporádicas do que frequentes; ao defenderem a solidariedade enquanto valor central subjacente às lutas sindicais transnacionais, não esqueciam, ao mesmo tempo, que nem sempre a solidariedade se impõe como princípio de ética política, tanto mais que "quanto mais necessária é a solidariedade mais difícil é o seu exercício” (Santos, 2001: 94); ao mencionarem a impor- 
tância dos apoios de ordem financeira, estavam, afinal, a constatar também que a sua recorrente ausência é um factor que explica o carácter ténue de uma PRI.

\section{A PRI da CGTP e da CUT}

A realização de um vasto leque de entrevistas a interlocutores da CGTP e da CUT, ${ }^{5}$ assim como a análise da documentação produzida por ambas as organizações, ${ }^{6}$ tornou possível assinalar as principais fases da PRI da CGTP e da CUT. No caso da CGTP, proponho uma estruturação da sua PRI em 3 fases: a primeira fase (1970-1989), situada entre a clandestinidade, a construção da democracia e a bipolarização ideológica (inerente a um clima de "Guerra Fria"), caracterizou-se pela afirmação e consolidação de uma natureza de classe que enaltece o "papel determinante da luta de classes na evolução histórica da humanidade” (CGTP, 2004c: 7); a segunda fase (1989-1995), situada entre a queda do Bloco de Leste e a filiação sindical transnacional, pautou-se por um repensar algo forçado da linha de rumo da PRI, em parte como resultado dos riscos de isolamento a que ficaram sujeitas muitas organizações sindicais comunistas em toda a Europa; e a terceira fase (de 1995 até ao presente), caracterizada quer por um novo relacionamento orgânico com o movimento sindical transnacional (entenda-se, sobretudo, com o movimento sindical europeu, por via da filiação na Confederação Europeia de Sindicatos, CES), quer pela conservação de um velho posicionamento de classe, traduzido na recuperação de bandeiras de luta antigas e no reforço da acção reivindicativa enquanto vector essencial da actuação dos sindicatos.

\footnotetext{
5 Junto das duas centrais sindicais, entrevistei sobretudo representantes do departamento internacional: secretários e ex-secretários de relações internacionais, assessores e consultores e ainda ex-assessores e ex-consultores desse mesmo departamento/secretaria internacional. Mas, além disso, entrevistei também sindicalistas de vários departamentos da CGTP e da CUT, com destaque para o departamento de formação sindical (departamento que, bem pode dizer-se, é uma espécie de "pólo intermediador" entre todas as áreas de intervenção das duas centrais sindicais), dirigentes de sindicatos e sectores ligados organicamente às duas centrais sindicais, ou ainda sindicalistas com responsabilidades directas de intervenção no âmbito das empresas multinacionais.

${ }^{6}$ A análise dos discursos transnacionais da CGTP incidiu, entre outros documentos, nos Programas de Acção dos Congressos, nos Relatórios de Actividades referentes ao espaço entre congressos, nos Estatutos, nas Intervenções de delegados em congressos nacionais da central ou mesmo em congressos da Confederação Europeia de Sindicatos (CES). A análise dos discursos transnacionais da CUT incidiu em documentos do mesmo tipo, tais como as Resoluções dos Congressos, os Cadernos de Teses preparatórios de Congressos ou de Plenárias Nacionais, as Resoluções das Plenárias Nacionais, as intervenções de delegados em congressos da central, bem como em congressos da Confederação Internacional dos Sindicatos Livres (CISL), por exemplo. Ainda no caso da CUT (onde há nitidamente mais documentação disponível sobre as "relações internacionais" do que no caso da CGTP), outros documentos foram objecto de consulta regular. Foi o caso do Boletim Mercosul, de alguns $\mathrm{Ca}$ dernos de Formação Sindical sobre o MERCOSUL ou da publicação Textos para Debate Internacional.
} 
Quanto à CUT, proponho uma estruturação da sua PRI em 5 fases: a primeira fase (1983-1988), pautada pela necessidade de afirmação da CUT e de dar a conhecer para o exterior o seu projecto sindical e político; a segunda fase (1988-1991), caracterizada pelo reforço da consolidação da CUT, que seria traduzido na elaboração consistente das primeiras directrizes de actuação internacional; a terceira fase (1991-1992), marcada pela decisão de ligação orgânica ao sindicalismo internacional, designadamente de filiação na CISL e na Organização Regional Interamericana de Trabalhadores (ORIT); a quarta fase (sobretudo desde 1992 até ao final da década/início do século XXI), concedendo uma relevância especial aos processos de integração regional, traduzida no apoio ao Mercado Comum do Sul (MERCOSUL) e na denúncia da Área de Livre Comércio das Américas (ALCA); e a quinta fase (do final dos anos 90/início do século XXI até ao presente), onde os caminhos de articulação com outras organizações da sociedade civil ganharam nova importância política, ainda que se tenham conservado sobretudo características da fase anterior.

\subsection{As fases da PRI da CGTP}

A primeira fase (1970-1989) ficou marcada por um período inicial de clandestinidade (ou, se preferirmos, por uma afirmação "secreta" da CGTP até 1974), assim como pela instauração da democracia e por um cenário político internacional de bipolarização ideológica (inerente ao contexto de "Guerra Fria"). Seria por certo mais realista situar o início desta fase não em 1970 mas em 1974, com todas as rupturas que o 25 de Abril introduziu na sociedade portuguesa, e com o consequente clima de liberdade sindical que expôs a CGTP aos "estímulos" internacionalistas. Porém, ainda que entre 1970 e 1974 não tenham sido formulados quaisquer pedidos de filiação sindical internacional por parte de sindicatos portugueses, o movimento intersindical desenvolveu acções conjuntas no sentido de se fazer representar na OIT e de ganhar o apoio do movimento sindical internacional (Costa, 1979: 232-233). Por isso, apesar do referido impedimento de facto criado pelo salazarismo/marcelismo ao internacionalismo sindical português, deve realçar-se a circunstância de a Intersindical (nome por que era conhecida a CGTP até 1977) ter começado ela própria a denunciar junto da OIT e de outras organizações sindicais internacionais esse mesmo impedimento ou conjunto de impedimentos logo em 1970. Daí a proposta de que a primeira fase da sua PRI se inicie em 1970, embora, obviamente, nesse período que vai até 1974 , as preocupações da central sindical fossem sobretudo preocupações políticas de afirmação nacional e de combate ao regime político da época. 
Nesta primeira fase, a PRI da CGTP revelou-se, efectivamente, ainda muito pouco estruturada, não obstante se aludisse já, sobretudo depois do 25 de Abril, a uma "política activa de unidade de acção e solidariedade entre todos os trabalhadores e os seus sindicatos à escala internacional" (CGTP, 1977: 42). Em termos genéricos, esta fase - na qual a influência do partido comunista sobre os órgãos de cúpula da central (Barreto, 1990: 108 ; 116) acabaria também por condicionar a própria PRI - caracterizou-se: pela afirmação e consolidação nacional da CGTP; pelo desenvolvimento de uma consciência de classe norteada pela defesa de um modelo socialista de sociedade; pelo apelo a uma solidariedade internacionalista entre trabalhadores, assente na rejeição de todas as formas de imperialismo, fascismo, colonialismo, neocolonialismo, racismo; pelo alinhamento ideológico com o sindicalismo dos países de Leste e com a FSM; pelo facto de a CGTP ter sido disputada pelas grandes organizações sindicais internacionais (sobretudo FSM e CISL); pelo forte sentimento nacionalista, assente na salvaguarda da independência nacional, num "amor revolucionário à pátria" (CGTP, 1977:39) e na rejeição de todo o tipo de actos de ingerência externa; pela luta contra a guerra e as armas nucleares; e ainda pela manifestação das primeiras críticas à $\mathrm{CEE}$, nomeadamente aos meios financeiros dela provenientes, aos interesses capitalistas e às políticas de actuação dos monopólios e das multinacionais a ela associadas.

A segunda fase da PRI da CGTP (1989-1995) ocorreu num contexto mundial de descrédito do modelo socialista, facto que obrigou a "repensar" as práticas sindicais da central (tradicionalmente sintonizadas com o bloco político-ideológico de Leste) e a equacionar a relação com outros destinos e actores. No entanto, apesar de a CGTP reconhecer a fraqueza do modelo social de Leste, não pareceu capaz, ela própria, de acompanhar o derrube da ideologia socialista. Por esse facto, continuou a elogiar o modelo social de Leste e a considerá-lo como o único capaz de suster a exploração capitalista, geradora de mais desemprego, mais desigualdades, mais pobreza, etc. (CGTP, 1989: 16). Seja como for, no quadro de uma avaliação sempre presente da conjuntura política e económica internacional e de uma melhor estruturação e definição de linhas orientadoras da PRI da CGTP, assente na definição de objectivos e prioridades concretos de acção internacional (luta pela paz; críticas às formas de dumping social; defesa dos direitos de emigrantes e imigrantes; luta contra o racismo e xenofobia, etc.), o processo de progressiva construção e integração europeia na CEE/UE passou a receber maior atenção por parte da central sindical. Ainda assim, a integração europeia foi quase sempre olhada de forma bastante crítica, pois temia-se que pusesse em causa o "Portugal democrático, 
desenvolvido, solidário e soberano" tão efusivamente defendido pela CGTP ao longo desta fase bem como para além dela (CGTP, 1993; 1996; 1999; 2003b).

Esta foi também uma fase que, aos poucos, tornou possível a definição de um novo relacionamento orgânico da CGTP com o movimento sindical transnacional, que conduziria (na fase seguinte) à filiação da CGTP na CES. Nesse sentido, na parte final desta segunda fase foi sendo concedida uma maior atenção à CES (no VII Congresso da CGTP, realizado em 1993, essa maior atenção à CES aparecia na sequência do pedido formal de filiação da CGTP na CES, apresentado em Novembro de 1992), ainda que a CGTP tenha aproveitado justamente esse espaço de maior atenção para, em forma de antecipação a esse convívio orgânico formal com a CES, ir lembrando quais deveriam ser as responsabilidades desta em matéria de combate ao racismo e xenofobia no quadro europeu e em matéria de abertura aos trabalhadores dos países de Leste, de modo a que a CES se configurasse como organização mais plural.

A terceira fase iniciou-se, pois, com a filiação da CGTP na CES, a 1 de Janeiro de 1995. Essa filiação vinha somar-se à participação que a central já evidenciara no quadro das instâncias comunitárias ainda na primeira fase da PRI da CGTP (no início da segunda metade dos anos 80). A PRI da CGTP passou a estar mais directamente confrontada quer com as orientações da CES, quer com as grandes questões relativas à evolução institucional da UE. Em si mesmo, o processo de filiação na CES abriu à partida, entre outras, as seguintes possibilidades para a CGTP: passar a ter um melhor conhecimento da CES; dispor de maiores contactos com diferentes concepções de sindicalismo e formas de pensar a UE; granjear um melhor reconhecimento externo por parte do sindicalismo europeu das potencialidades e representatividade da CGTP; ter acrescida capacidade para influenciar as políticas da CES e a sua lógica organizativa interna; levar para a CES o "espírito" mobilizador da CGTP.

No entanto, estar na Europa não significou estar com a Europa, uma vez que a CGTP não abdicou da sua atitude tradicionalmente crítica quer para com a CES, quer para com os caminhos da UE, ainda que, a espaços, pareça existir alguma suavização dessa posição (por exemplo, abordar o tópico da "negociação europeia" poderá constituir um sinal nesse sentido, ainda que a forma de o fazer seja sempre através do reforço da componente reivindicativa típica da CGTP e não da assunção de uma atitude institucionalista). Como tal, a posição crítica face aos caminhos da UE tem sido uma constante ao longo dos vários congressos da central e ao longo das fases da sua PRI. Desde 1999, com a entrada em vigor da $3^{\text {a }}$ fase da União Económica e 
Monetária (UEM), a CGTP considera que foram postas em evidência algumas das dificuldades do processo de integração europeia: incumprimento do Pacto de Estabilidade e Crescimento; reforço de uma política monetarista; predomínio de teses neoliberais nos vários centros de decisão (CGTP, 2004a: 7). Afinal, "desde o V Congresso que a CGTP-IN definiu o processo de integração europeia como correspondendo à fase actual do desenvolvimento do sistema capitalista, na Europa tendo como elementos centrais a livre circulação de capitais e a liberalização e desregulamentação, como factores de concentração e centralização capitalista a favor das grandes potências no quadro da sua competição com os EUA e o Japão" (CGTP, 2004b: 75).

Mas esta terceira fase da PRI da CGTP confirmou também uma forte preocupação com a defesa de uma solidariedade internacional respeitadora da soberania dos povos, em nome da defesa do socialismo e dos seus valores e contra a globalização neoliberal e as empresas multinacionais que enfraquecem cada vez mais o papel do Estado nas sociedades contemporâneas. $\mathrm{Na}$ linha das fases anteriores, nesta fase tem-se igualmente intensificado um discurso e uma prática contra a guerra e em prol da paz, objectivos que, em simultâneo, têm aberto caminho a uma crescente cooperação, ainda que a meu ver tímida, entre a CGTP e outras organizações sociais não sindicais com objectivos convergentes. Com efeito, a relação capital-trabalho como eixo da luta de classes continua a ser assumida como referência-chave de actuação da CGTP. Assim, ao mesmo tempo que busca manter um esforço de intervenção de toda a estrutura da CGTP na vida regular da CES, a CGTP não deixa de ter presente que é indispensável dotar essa mesma estrutura de um maior conhecimento sobre as evoluções do movimento sindical internacional e sobre o papel histórico da classe operária nesse movimento.

\subsection{As fases da PRI da CUT'}

Constituída em 1983 com o intuito de romper com os padrões políticos do passado e permitir aos trabalhadores expressarem-se como "sujeitos políticos independentes na vida nacional" (CUT, 1984a: 8), o objectivo prioritário inicial da CUT consistiu na unificação de lutas no Brasil (Giannotti e Neto, 1990: 54-57). Assim, a primeira fase da PRI da CUT (1983-1988) caracterizou-se sobretudo por uma afirmação nacional da central e por um reconhecimento por parte de outras organizações sindicais internacionais (nomeadamente europeias) da importância do projecto sindical e político de tipo

\footnotetext{
${ }^{7}$ Para uma análise mais demorada destas fases, cf. Costa (2005a).
} 
novo protagonizado pela CUT. As principais bandeiras de luta desta fase que fizeram apelo a uma solidariedade internacional e se traduziram na realização de encontros entre trabalhadores latino-americanos foram as campanhas pelo não pagamento da dívida externa dos países da América Latina e os ataques às imposições do Fundo Monetário Internacional (FMI) (CUT, 1984b: 2).

Apesar de já se envolver em "estratégias internacionais e articuladas do movimento sindical” (CUT, 1986: 23), a CUT conservava a sua posição de autonomia sindical relativamente às centrais sindicais internacionais ou regionais, preferindo continuar os seus contactos bilaterais com diversas centrais sindicais mundiais com o intuito de salvaguardar a luta da classe trabalhadora a nível internacional e o respeito pelos seus princípios de classe. Assim, nesta primeira fase, não obstante a defesa de um discurso internacionalista assente na solidariedade de classe, na luta pela autodeterminação dos povos ou na defesa da paz, "a CUT não chegou a formular uma política clara que estabelecesse os objectivos tácitos e estratégicos das suas relações internacionais, restringindo a sua actuação ao campo da diplomacia e à busca da solidariedade e do reconhecimento internacional" (CUT, 1992: 6). Tratou-se, pois, se assim pode dizer-se, de uma fase preparatória da PRI, onde a busca de uma identidade sindical nacional em torno do "projecto CUT" constituía a orientação prioritária da central. A actuação internacional da CUT estava muito dependente "dos discursos, dos documentos e das intenções dos dirigentes" e, nesse sentido, "a CUT tinha relações internacionais mas não tinha política de relações internacionais". Nesta fase - a meio da qual (em 1985) se deu o derrube da ditadura militar para o qual a central muito contribuiu -, a CUT envolveu-se sobretudo em acções de solidariedade internacional para com o povo da Palestina, de Cuba, do Chile, do Paraguai, da Nicarágua, para com o Solidarnosc da Polónia, etc.

A segunda fase da PRI (1988-1991) da CUT ocorreu num contexto de consolidação da sua lógica organizativa, tendo sido uma fase que conferiu um impulso decisivo à sua PRI e ditou o seu verdadeiro arranque. Para além de se reforçarem as acções de solidariedade internacional da fase anterior, era agora delineada por parte da Secretaria de Relações Internacionais da CUT (SRI/CUT) uma estratégia internacional própria, assente numa intensificação de relações bilaterais (sobretudo com centrais sindicais latino-americanas, mas também europeias) ou na interiorização das relações

\footnotetext{
${ }^{8}$ Ex-secretário de relações internacionais da CUT (entrevista, Junho de 2001, São Paulo, Sede da CUT).
} 
internacionais junto das diferentes instâncias da CUT (CUT, 1992: 6-7). Nesta fase, manteve-se igualmente uma posição de autonomia orgânica face às principais confederações sindicais mundiais (CISL, FSM e CMT), não só devido à escassez de informação que a CUT ainda considerava ter a respeito do sindicalismo internacional em geral e daquelas centrais sindicais em particular, como também porque "o grande desafio histórico do movimento sindical latino-americano era o de construir a sua própria unidade de acção e de luta diante da crise internacional e da dívida externa" (CUT, 2003b: 33).

Parece, pois, legítimo situar o verdadeiro início da PRI da CUT nesta fase. E se se analisar em pormenor o próprio Caderno de Teses preparatório do $3^{\circ}$ Congresso Nacional da CUT (CONCUT), observa-se mesmo nele uma posição da corrente principal da CUT - a Articulação Sindical - sobre os assuntos internacionais. Como lembra Leôncio Martins Rodrigues (1990: 108), ao contrário das restantes teses, esta tese iniciava-se com uma análise da conjuntura internacional, "marcada por mudanças estruturais na dinâmica do capitalismo e pela perspectiva de agravamento da crise económica mundial" (CUT, 1988: 49). Nesse contexto adverso, a CUT afirmava ainda que "o sentimento anti-imperialista e as reivindicações democráticas e populares dependem cada vez mais da capacidade de a classe trabalhadora se organizar". E, não obstante as inúmeras dificuldades então sentidas pelo movimento sindical e popular em articular a luta quotidiana dos trabalhadores, eram considerados "inegáveis os grandes avanços políticos dos trabalhadores em todo o continente latino-americano" (CUT, 1988: 50).

A terceira fase da PRI da CUT (1991-1992) foi aquela em que a central sindical brasileira definiu um vínculo orgânico formal ao sindicalismo transnacional, quer por via da sua filiação numa organização sindical internacional, a CISL, quer por via da sua adesão a uma organização sindical regional, a ORIT. O facto de, até aí, a CUT não estar filiada em qualquer organização sindical mundial terá diminuído a sua capacidade de intervenção e de influência nos fora sindicais internacionais, pois a participação em tais fora só tinha lugar mediante convite e resumia-se, basicamente, a discursos de saudação. O $4^{\circ}$ CONCUT (1991) deliberou, então, que na $5^{a}$ Plenária Nacional da CUT (realizada em Julho de 1992) se escolheria qual a confederação sindical internacional onde a CUT se filiaria e se definiria uma PRI clara e capaz de conferir à CUT uma maior capacidade de intervenção internacional e uma melhor interferência nos processos de transformação económica e social em curso (CUT, 1991: 8).

Com a filiação internacional, delinearam-se, assim, novas prioridades de actuação internacional: intensificação da relação com a América Latina; 
aprofundamento das relações bilaterais com as centrais sindicais europeias; o desenvolvimento de acções articuladas a partir das organizações por local de trabalho; a interiorização das relações internacionais junto das diferentes instâncias da CUT (CUT, 2003b: 52-53).

A quarta fase da PRI da CUT (de 1992 até ao final dos anos 90/princípio do século XXI) ficou marcada quer pela defesa do MERCOSUL, quer ainda (nessa sequência e em simultâneo) pelo forte combate à ALCA. A preocupação com o MERCOSUL esteve, desde logo, bem patente desde o $5^{\circ}$ CONCUT (1994). Perante um projecto de integração "calcado na liberalização comercial” (CUT, 1994b: 6), o lema da CUT para o MERCOSUL era o de "fazer a nossa integração" (CUT, 1994a: 29; 1994b: 38), ou seja, ir ao encontro de um espaço efectivo para a actuação sindical. Este interesse no MERCOSUL (que ainda hoje se mantém vivo) visou sobretudo fazer com que aquela união aduaneira se dotasse de preocupações laborais e sociais e não apenas de preocupações económicas, o que passaria, claro está, por lutar por um espaço de intervenção para o movimento sindical. Esta preocupação com o MERCOSUL contribuiu também, em minha opinião, para que a CUT reforçasse o seu papel de liderança no quadro do sindicalismo latino-americano em geral e no Cone Sul em particular (sobretudo através da sua participação no seio da Coordenadora das Centrais Sindicais do Cone Sul, CCSCS).

Na 9ª Plenária Nacional da CUT (em 1999), um tema que, não sendo novo, emergiu contudo com força a partir de então foi a defesa de uma unidade continental de trabalhadores para combater a ALCA. Segundo a CUT, o objectivo da ALCA resume-se a "transformar todo o hemisfério num verdadeiro quintal norte-americano, com total liberdade de mercado para seus capitais, produtos e uma superexploração da classe operária" (CUT, 1999: 40). Assim, o combate à ALCA, ao mesmo tempo que se transformou num pretexto para reforçar a luta pela defesa do MERCOSUL, serviu de mecanismo de alerta para todo o tipo de atropelos aos direitos laborais decorrentes de uma entrada em vigor de um bloco estritamente comercial alargado praticamente a todo o hemisfério americano.

A quinta fase da PRI da CUT (de final dos anos 90/princípio do século XXI até à actualidade) tem dado continuidade quer à defesa do MERCOSUL, quer sobretudo ao combate à ALCA, temas que se destacaram na fase anterior da sua PRI. Em especial desde Janeiro de 2001 (com a realização da $1^{a}$ edição do Fórum Social Mundial, FOSM), a CUT entrou numa nova fase da sua PRI - que designo como fase do "internacionalismo sindical solidário" -, ainda que ela esteja longe de romper com a fase anterior, pois na quinta fase o discurso simultâneo de defesa do MERCOSUL e 
de combate à ALCA é inclusive reforçado. Aliás, e como argumento para justificar a articulação entre fases, direi mesmo que esta quinta fase - que, repito, a meu ver se tornou efectiva a partir de 2001 (pois o $1^{\circ}$ FOSM confirmaria mundialmente uma prática da CUT de alianças sociais amplas), ainda que, no final de 1999, Seattle tenha constituído um primeiro sinal global claro de congregação de uma "energia política antiglobalização" onde a CUT também esteve presente (CUT, 2003b: 108) - é o corolário de um "período de grande diversificação da actuação internacional da CUT" registado já a partir de 1995 (CUT, 2003b: 77).

Ao mesmo tempo que defende o MERCOSUL e combate a ALCA, a fase actual do internacionalismo sindical solidário concretiza-se numa "unidade de sectores sociais internacionais amplos" (CUT, 2001: 20; 2002: 3). Como observava o secretário de relações internacionais da CUT na $3^{a}$ edição do FOSM (Janeiro de 2003):

O objectivo político e o respeito mútuo nas organizações de constituir essa intervenção comum é o que nos orienta e o que nos permite estar na organização desse Fórum Social Mundial desde a primeira edição, como estivemos em Seattle, como estivemos em Génova, como estivemos nas diversas manifestações do mundo. Portanto, nós, da CUT, queremos um movimento sindical absolutamente forte, sintonizado com o nosso tempo e organizado internacionalmente e em aliança com outros movimentos. ${ }^{9}$

Ou seja, a CUT não deixou de considerar o sindicalismo enquanto actor social de maior peso no conjunto dos movimentos sociais. Aliás, um domínio onde tem vindo a reforçar a sua intervenção é o do combate às multinacionais, ou não fossem estas "o verdadeiro motor da globalização neoliberal” (CUT, 2002: 2; 2003a: 7). Mas tem-no feito não só em conjunto com outras organizações sindicais - nomeadamente em projectos como o "Acção frente às multinacionais: construindo redes sindicais nas empresas multinacionais" 10 ou em iniciativas de aplicação das Directrizes para as multinacionais da Organização para a Cooperação e Desenvolvimento

\footnotetext{
${ }^{9}$ Depoimento recolhido no painel "Sindicalismo e movimento social vs capitalismo neoliberal: necessitamos de novas formas de organização contra novas formas de capitalismo?" (Porto Alegre, 26.01.2003). De entre os actores sociais não sindicais com que o sindicalismo cutista partilha a sua agenda e estratégias de luta, destacam-se: organizações de defesa do ambiente, de luta contra o racismo, de defesa de múltiplas orientações sexuais, dos trabalhadores sem terra, etc., etc.

${ }_{10}$ Trata-se de um projecto que, como a própria designação indica, visa a constituição de redes sindicais de troca de informação entre trabalhadores das diversas fábricas de uma mesma multinacional que operam no Brasil, de modo a criar um diálogo com a empresa e a fortalecer a posição dos trabalhadores nas negociações com as multinacionais (CUT, 2003c: 1).
} 
Económico (OCDE) ${ }^{11}$ (CUT, 2003b: 115-117) -, como em articulação com outras organizações da sociedade civil. Por exemplo, fiscalizar se as empresas multinacionais com filiais no Brasil cumprem as normas sociais e ambientais básicas da OIT é um trabalho realizado no quadro do "Observatório Social" da CUT (criado em 1998), iniciativa liderada pela CUT e que reúne conjuntamente sindicatos, centros de investigação, departamentos de estatística do trabalho, redes universitárias, etc. Ou seja, ao mesmo tempo que funciona como um importante instrumento de apoio e de informação para a SRI/CUT, o "Observatório Social" parece seguir também os caminhos de um internacionalismo sindical solidário. O facto de no $8^{\circ}$ CONCUT (Junho de 2003), entre as delegações internacionais convidadas, terem estado pela primeira vez entidades não sindicais vem confirmar a abertura da central neste domínio, tornando possível reforçar e delinear novos desafios conjuntos com outros movimentos sociais transnacionais.

\section{Semelhanças e diferenças entre a PRI da CGTP e da CUT}

Depois de sistematizar aquelas que, a meu ver, são as principais fases e os principais temas da PRI da CGTP e da CUT, pretendo agora assinalar alguns pontos de convergência e de divergência entre a PRI das duas centrais sindicais. De entre as principais semelhanças destaco as seguintes:

1. A PRI é uma política que tem "vida própria" no interior de cada central sindical, i.e., está vinculada a um departamento/secretaria responsável directa e autonomamente pelo tratamento dos assuntos internacionais. Ainda assim, a PRI está inevitavelmente ligada a outras políticas e departamentos com preocupações de intervenção nacional (como a formação sindical, a acção reivindicativa, as relações de género e a igualdade de oportunidades, etc.);

2. O lugar ocupado pela PRI é muito residual em ambas as centrais sindicais, o que se explica por factores como: a prioridade quase absoluta concedida aos temas nacionais; o pouco à vontade na definição e caracterização da PRI; a escassez de verbas para dinamizar contactos internacionais; a escassez de debates e reflexões internas sobre a importância das relações internacionais;

3. A PRI tende a ser vista com uma espécie de prolongamento das preocupações nacionais das centrais (o que vem corroborar em parte o que foi mencionado no ponto 1);

\footnotetext{
${ }_{11}$ Aproveitando o facto de o Brasil ter aderido, no final de 1999, a essas orientações da OCDE, a CUT tem vindo a exercer uma pressão sobre as multinacionais para que estas cumpram as normas internacionais relativas ao mundo do trabalho.
} 
4. A PRI da CGTP e da CUT tende a privilegiar as dinâmicas regionais, quer as decorrentes da intervenção sindical no quadro da UE (no caso da CGTP), quer as decorrentes da intervenção sindical no quadro do MERCOSUL e América Latina (no caso da CUT). Esta apetência "natural" para privilegiar os blocos regionais em que cada uma se encontra inserida explica, em boa medida, o recíproco "voltar de costas" (i.e., a escassez de intercâmbio directo) entre o sindicalismo português e o sindicalismo brasileiro;

5. Os processos de filiação sindical transnacional em organizações sindicais transnacionais foram determinantes na estruturação das fases da PRI;

6. A PRI da CGTP e da CUT tem tido como prioridades de intervenção ao longo dos anos: o combate à globalização económica neoliberal, às empresas multinacionais e às instituições de crédito que lhe estão associadas e que são responsáveis pelo declínio dos poderes do Estado; o apelo à inclusão de uma "dimensão social" nos processos de integração regional; o combate a todas as formas de dumping social; o apelo à adopção de formas de "responsabilidade social" por partes das multinacionais no quadro de uma defesa ampla de padrões laborais mínimos (nos termos definidos pela OIT e OCDE); a luta pela paz mundial e solidariedade entre os povos; a luta contra o racismo e xenofobia e todas as formas de discriminação no trabalho; a defesa de uma "globalização solidária", em nome de uma agenda progressista capaz de transformar as sociedades; etc.

No que diz respeito às principais diferenças que detectei entre a PRI da CGTP e da CUT, destaco as seguintes:

1. A PRI da CGTP está ainda muito "colada" a um sindicalismo made in Portugal (assente num reincidente discurso de defesa da soberania nacional e da independência nacional), ao passo que a PRI da CUT, apesar de conter também uma "marca" nacional (brasileira) e de, portanto, partir dos temas e preocupações nacionais, acaba por se "soltar" mais deles;

2. A coabitação da CGTP com processos de integração regional institucionalmente mais consolidados tem sido menos pacífica do que sucede com a CUT, não obstante esta conviver com processos de integração regional institucionalmente menos consolidados;

3. Face à UE e à integração europeia, a CGTP tem apostado em privilegiar a crítica em detrimento da participação (i.e., uma crítica acompanhada de participação), ao passo que a CUT, sem deixar de criticar a subvalorização da dimensão social do processo de integração regional no MERCOSUL, parece privilegiar a participação em detrimento da crítica (i.e., uma participação acompanhada de crítica); 
4. A PRI da CGTP tende a valorizar um internacionalismo sindical "puro" por considerar que os actores sindicais são porventura os únicos capazes de transformar a sociedade, ao passo que a PRI da CUT, embora confira de igual modo ao sindicalismo o principal papel de transformação da sociedade, abre também a porta a múltiplas experiências de diálogo como outras organizações da sociedade civil, fazendo jus a um internacionalismo sindical solidário;

5. Na CGTP são menores as tradições de ligação ao sindicalismo latino-americano, ao passo que na CUT são maiores as tradições de ligação ao sindicalismo europeu;

6. A PRI da CGTP evidencia uma grande continuidade no que diz respeito aos temas e problemáticas de intervenção transnacional que vem defendendo. Tal facto é revelador de uma consistência de princípios, ainda que retire espaço à inovação e à diversificação da PRI e das suas etapas. A CUT, por seu lado, apesar de constituída depois da CGTP, parece ter estimulado maiores debates no seu seio a propósito da PRI, o que explica, em parte, uma maior diversidade de fases e de temas que percorrem a PRI, não obstante também conservar ao longo dos anos temas repetidos (o combate ao pagamento da dívida externa dos países da América Latina é apenas um exemplo disso);

7. A CGTP tem reconhecido a necessidade de uma progressiva articulação entre políticas no seio da central (envolvendo a PRI e outras políticas), ainda que, por exemplo, a sua política de formação sindical não reserve módulos de formação sindical específicos sobre a PRI. Por sua vez, a CUT reconhece igualmente a necessidade de articulação interna entre políticas, embora reserve espaços de formação específicos a respeito das questões internacionais, o que, por consequência, facilita a interiorização da própria PRI na estrutura da central.

\section{Conclusão}

Ao terminar esta incursão pela PRI da CGTP e da CUT, queria ainda enunciar alguns desafios que emergem dessa política para ambas as centrais sindicais. Em meu entender, a PRI da CGTP tem pela frente pelo menos três desafios: primeiro, o desafio da partilha dos assuntos internacionais por toda a estrutura da central, para o qual a realização de plenários descentralizados em articulação com a maximização de uma política de formação sindical podem constituir um instrumento valioso; segundo, o desafio da superação do internacionalismo sindical nacional/soberano, só possível de concretizar mediante um exercício, sem dúvida arrojado ideologicamente, de uma maior valorização de opções transnacionais (a começar pelas 
europeias) em detrimento de um excessivo apego às raizes nacionais (ainda muito apoiadas na defesa da soberania nacional); terceiro, o desafio da adopção regular e consistente de um sindicalismo de movimento social transnacional, com base no chamado "movimento de movimentos" de contestação à globalização neoliberal nascido em Seattle e confirmado nas cinco edições do Fórum Social Mundial já realizadas.

Por sua vez, considero que a PRI da CUT se confronta hoje com dois desafios: primeiro, o desafio da criação de um "ponto de equilíbrio" entre uma PRI de pendor claramente contra-hegemónico (que, por esse facto, parece atenuar ou compensar os atritos nacionais entre as diferentes correntes internas da CUT) e uma atitude de intervenção nacional que hoje, nunca como outrora, apresenta um cariz mais institucional e pró-hegemónico do ponto de vista político (por via da proximidade ao governo Lula); segundo, o desafio decorrente das novas configurações sócio-económicas resultantes da (mais do que) provável confirmação de uma "era pós-MERCOSUL”. Estará o MERCOSUL condenado a ser "engolido" pela ALCA, abalando, dessa forma, todo o esforço de luta depositado pela CUT nas suas duas últimas fases da PRI? Ou, ao contrário disso, e caso a ALCA veja de facto a luz do dia, continuará o MERCOSUL a funcionar como referência para o sindicalismo cutista, configurando-se, assim, como um "destino" para os trabalhadores e sindicatos ligados à CUT, para os quais só através do MERCOSUL a soberania do Brasil não ficará ameaçada (ou, pelo menos, tão ameaçada)?

Para ambas as centrais sindicais, conferir uma voz e uma praxis a um sindicalismo de língua portuguesa (Costa, 2002: 87-89), assente em contactos bilaterais directos entre CGTP e CUT, constitui, a meu ver, um dos desafios mais aliciantes para a PRI das duas organizações sindicais nacionais. Trata-se de um desafio que pressupõe pôr em prática uma atitude regular e recíproca de "aprender com o outro", isto é, uma atitude de aprendizagem recíproca do sindicalismo português com o brasileiro e do sindicalismo brasileiro com o português. Neste sentido, o sindicalismo português poderia aprender com o brasileiro a: valorizar e dinamizar mais "experiências de base"; conceder um espaço mais amplo ao debate de ideias com outras organizações não sindicais da sociedade civil; estimular uma abertura do movimento sindical à cooperação com universidades e centros de investigação. Por outro lado, e não obstante a frágil europeização da negociação colectiva portuguesa, o sindicalismo brasileiro poderia aprender com o modo como o sindicalismo português (e aqui não só a CGTP, mas também a UGT) se vem progressivamente integrando em instâncias sociais europeias há mais tempo consolidadas, como a CES, as Federações Sindi- 
cais Europeias, o Comité Económico e Social da UE, ou mesmo a OIT, sediada na Europa. Tratar-se-ia, por certo, de uma referência útil para a actuação do sindicalismo brasileiro no quadro de instâncias sociais do MERCOSUL, como a CCSCS, o Subgrupo 10 (assuntos trabalhistas, emprego e segurança social) ou o Fórum Consultivo Económico-Social, entre outras.

Falta, pois, acrescentar à convergência ideológica e programática já existente entre a CGTP e a CUT uma cooperação bilateral mais efectiva, traduzida em projectos, acções e iniciativas públicas comuns. Essa seria não só uma forma de aproximar o sindicalismo dos dois países, como de dinamizar a PRI das duas mais importantes centrais sindicais de expressão portuguesa.

\section{Siglas}

ALCA, Área de Livre Comércio das Américas

CCSCS, Coordenadora das Centrais Sindicais do Cone Sul

CES, Confederação Europeia de Sindicatos

CGTP, Confederação Geral dos Trabalhadores Portugueses

CISL, Confederação Internacional dos Sindicatos Livres

CMT, Confederação Mundial do Trabalho

CONCUT, Congresso Nacional da CUT

CUT, Central Única dos Trabalhadores

FMI, Fundo Monetário Internacional

FOSM, Fórum Social Mundial

FSM, Federação Sindical Mundial

MERCOSUL, Mercado Comum do Sul

OCDE, Organização para a Cooperação e Desenvolvimento Económico

OIT, Organização Internacional do Trabalho

PRI, Política de Relações Internacionais

SRI/CUT, Secretaria de Relações Internacionais da CUT

UE, União Europeia

UGT, União Geral de Trabalhadores

\section{Referências Bibliográficas}

Barreto, José (1990), "Os primórdios da Intersindical sob Marcelo Caetano", Análise Social, XXV (105/106), 57-117.

CGTP (1977), Programa de ação aprovado pelo Congresso de Todos os Sindicatos (27 a 30 de Janeiro de 1977). Lisboa: Edições Alavanca. 
CGTP (1989), Plataforma para a acção sindical (1989-1992). VI Congresso. Lisboa: CGTP.

CGTP (1993), Programa de acção. VII Congresso. Lisboa: CGTP.

CGTP (1996), Programa de acção. VIII Congresso. Lisboa: CGTP.

CGTP (1999), Programa de acção e resoluções. IX Congresso. Lisboa: CGTP.

CGTP (2003a), Posição da CGTP-IN face à proposta de revisão dos Tratados saídos da Convenção Europeia. Lisboa: CGTP.

CGTP (2003b), Propostas de alteração aos estatutos. X Congresso. Lisboa: CGTP, 1-30.

CGTP (2004a), Relatório de actividades. X Congresso. Lisboa: CGTP.

CGTP (2004b), Programa de acção. X Congresso. Lisboa: CGTP.

CGTP (2004c), Estatutos. X Congresso. Lisboa: CGTP.

Costa, Hermes Augusto (2002), “A acção sindical na UE e MERCOSUL: limites e desafios”, Revista Crítica de Ciências Sociais, 62, 69-96.

Costa, Hermes Augusto (2005a), "Sindicalismo e política internacional: o caso da CUT", Lua Nova, 64.

Costa, Hermes Augusto (2005b), "Enlarging the Canon of Labour Internationalism", in B. S. Santos (org.), Another Production Is Possible: Beyond the Capitalist Canon. London: Verso (no prelo).

Costa, Ramiro da (1979), Elementos para a história do movimento operário em Portugall 1930-1975. $2^{\circ}$ volume. Lisboa: Assírio \& Alvim.

CUT (1984a), I Congresso Nacional da Classe Trabalbadora. Rio de Janeiro: Tempo e Presença Editora.

CUT (1984b), Jornal da CUT, Ano II, 1. São Paulo: CUT.

CUT (1986), Resoluções do $2^{\circ}$ CONCUT. São Paulo: CUT.

CUT (1988), Caderno de teses para o $3^{\circ}$ Congresso da CUT ( $2^{a}$ edição revista e ampliada). São Paulo: CUT.

CUT (1991), Resoluções do $4^{\circ}$ CONCUT. São Paulo: CUT.

CUT (1992), Política de relações internacionais. São Paulo: CUT.

CUT (1994a), Tese base para o $5^{\circ}$ CONCUT. São Paulo: CUT.

CUT (1994b), Resoluções do $5^{\circ}$ CONCUT. São Paulo: CUT.

CUT (1999), Resoluções da $9^{a}$ Plenária Nacional da CUT. São Paulo: CUT.

CUT (2001), Texto base da $10^{a}$ Plenária Nacional. São Paulo: CUT.

CUT (2002), "Relações internacionais”, in Resoluções da 10ª Plenária Nacional (http:// www.cut.org.br/10plencut/polper.htm), 1-6, acedido em 21.03.2003.

CUT (2003a), Texto base da direcção nacional. $8^{\circ}$ CONCUT (http://www.cut.org.br), 1-54, acedido em 2.04.2003.

CUT (2003b), A política internacional da CUT. História e perspectivas (http:// www.cut.org.br), 1-132, acedido em 4.07.2003.

CUT (2003c), "Projecto «Acção frente às multinacionais. Construindo redes sindicais nas empresas multinacionais" (http://www.cut.org.br/SRI/projeto_CUT_FNV.htm), 1-3, acedido em 13.06.2003. 
Estanque, Elísio (2000), Entre a fábrica e a comunidade: Subjectividades e práticas de classe no operariado do calçado. Porto: Afrontamento.

Giannotti, Vito; Neto, Sebastião Lopes (1990), CUT, por dentro e por fora. Petrópolis: Vozes.

Hobsbawm, E. J. (1988), “Working-class Internationalism”, in Frits van Holthoon; Marcel van der (orgs.), Internationalism in the Labour Movement 1830-1940. Volume I. Leiden: E. J. Brill, 3-16.

MacShane, Denis (2004), "Foreword", in R. Munck (org.), Labour and Globalisation: Results and Prospects. Liverpool: Liverpool UP, viii-xi.

Munck, Ronaldo (2002), Globalisation and Labour: The New "Great Transformation". London: Zed Books.

Pasture, Patrick; Verberckmoes, Johan (1998), "Working-class Internationalism and the Appeal of National Identity: Historical Dilemmas and Current Debates in Western Europe", in P. Pasture; J. Verberckmoes (orgs.), Working-class Internationalism and the Appeal of National Identity: Historical Debates and Current Perspectives on Western Europe. Oxford: Berg, 1-41.

Rodrigues, Leôncio Martins (1990), CUT: os militantes e a ideologia. Rio de Janeiro: Paz e Terra.

Santos, Boaventura de Sousa (2001), A cor do tempo quando foge. Crónicas, 1985-2000. Porto: Afrontamento.

Santos, Boaventura de Sousa; Costa, Hermes Augusto (2004), "Introdução: para ampliar o cânone do internacionalismo operário", in B. S. Santos (org.), Trabalhar o mundo: os caminhos do novo internacionalismo operário. Porto: Afrontamento, 17-61.

Thompson, E. P. (1987), A formação da classe operária inglesa. Rio de Janeiro: Paz e Terra.

Waterman, Peter (1998), Globalisation, Social Movements \& the New Internationalisms. London: Mansell. 